\title{
Gastric Duplication Cyst: Three Cases Report
}

\author{
S. Bezzanin*, L. Aqqaoui, H. Oubeja, H. Zerhouni, M. Erraji, F. Ettayebi
}

Department of Emergency Pediatic Surgey, Children's Hospital, Faculty of Medicine and Pharmacy, Rabat, Morocco

DOI: $10.36347 /$ simcr.2020.v08i07.001

| Received: 07.06.2020 | Accepted: 15.06.2020 | Published: 11.07.2020

*Corresponding author: Sabra Bezzanin

Abstract

Case Report

Duplication of the alimentary tract is a rare congenital anomaly. Gastric duplication cysts (GDCs) represent $4 \%$ of all alimentary tract duplications, and approximately $67 \%$ manifest within the first year of life. Herein, we report three cases of symptomatic GDC presenting in childhood. In the three cases the duplication was symptomatic; the exam revealed middle epigastric tenderness; The CT Scan confirms the diagnosis. Exploratory laparotomy with sub total resection of the duplication with mucoclasya were performed. Pathology in three cases was diagnostic of GDC.

Keywords: Gastric, Duplication, Custs, Resection.

Copyright @ 2020: This is an open-access article distributed under the terms of the Creative Commons Attribution license which permits unrestricted use, distribution, and reproduction in any medium for non-commercial use (NonCommercial, or CC-BY-NC) provided the original author and source are credited.

\section{INTRODUCTION}

Duplication of the alimentary tract is a relatively rare congenital anomaly. It can affect any part of the gastrointestinal tract with ileum being the most common site $[1,2]$. These malformations are believed to be congenital, formed before the differentiation of epithelial lining, and therefore named for the organ with which they are associated [3]. Duplication cysts of the stomach represent four per cent of all alimentary tract duplications. Approximately 67 per cent of gastric duplication cysts (GDCs) are identified within the first year of life [4]. Herein, we report three cases of symptomatic duplication cysts of stomach.

\section{Patients And Odservations} Case-1

A 2 months male presented with a 10 days history of vomiting and constipation. Physical examination revealed an hypogastric tendreness with a vague palpable masse. Ultrasound and ct scan of the abdomen demonstrated a cyst mass without any other mass or lymphadenopathy, (Fig-1) the opacifaction of the gastric tructshowed the mass and the side effect. On exploratory laparotomy a soft cystic mass measuring 8 $\mathrm{cm}, 6 \mathrm{~cm}$ was founded and excisied. The follow up was simple.

\section{Case-2}

A 10 months male was admited with intussusception as first diagnosis, the physical exams showed an epigastric mass. The ultrasoud showed an epigastirc mass in contact with duodenuma measuring

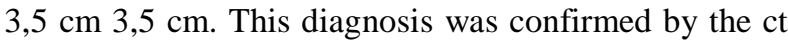
scan. Laparotomy founded a cyst mass, it was excisied with mucoclasia (Fig $2 \& 3$ ). The anatomopathology exam confirmed the diagnosis. The follow up was simple.

Case-3

A 1 year female presented with an epigastric mass diagnosis adventitiously by her pediatric doctor. The exam founded an tendreness with a palpable mass. The ultrasound and ct scan demonstrated a cyst mass without any other mass. Exploring laparotomy confiremed the diagnosos an excision with mucoclasia was practiced the follow up was simple (Fig-4). 


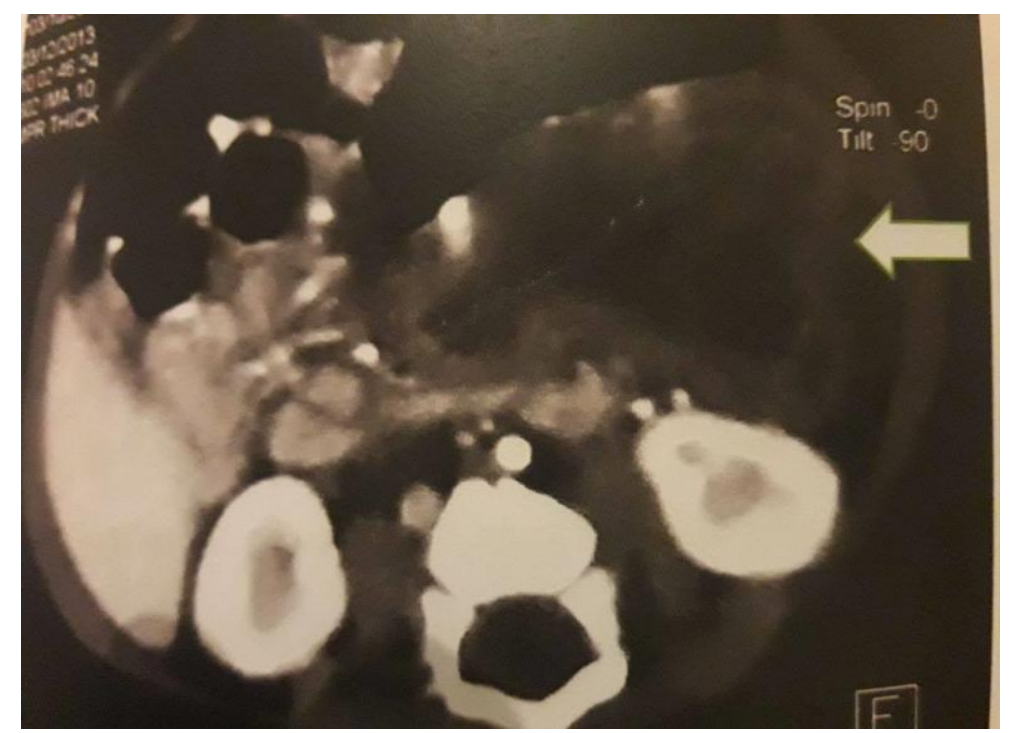

Fig-1: Scan of the abdomen demonstrated a cyst mass without any other mass or lymphadenopathy

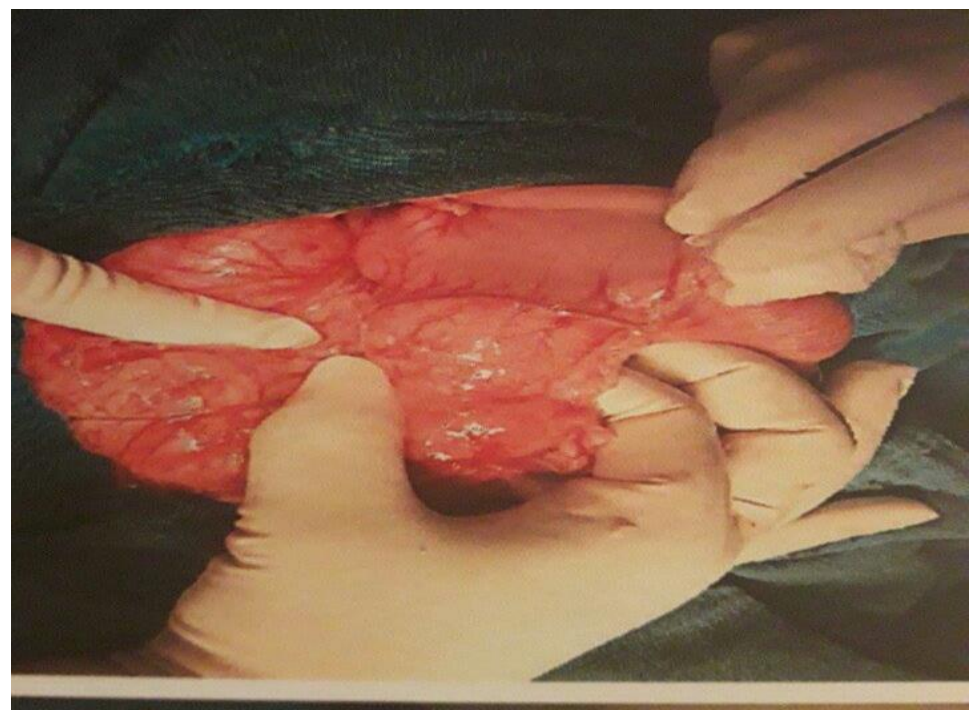

Fig-2: Laparotomy founded a cyst mass, it was excisied with mucoclasia

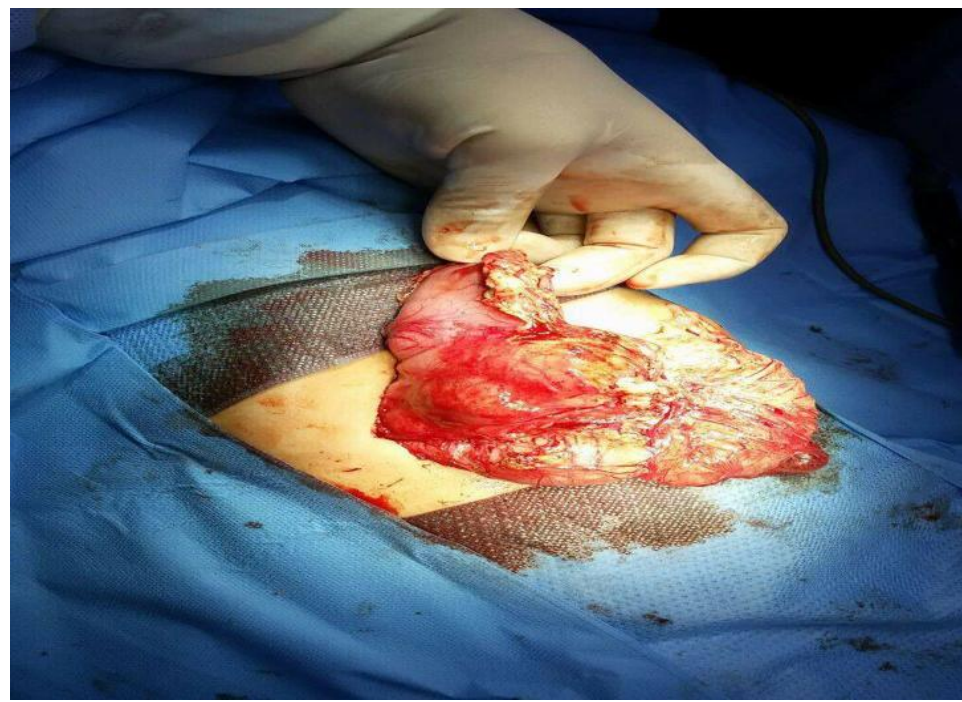

Fig-3: Laparotomy founded a cyst mass, it was excisied with mucoclasia 


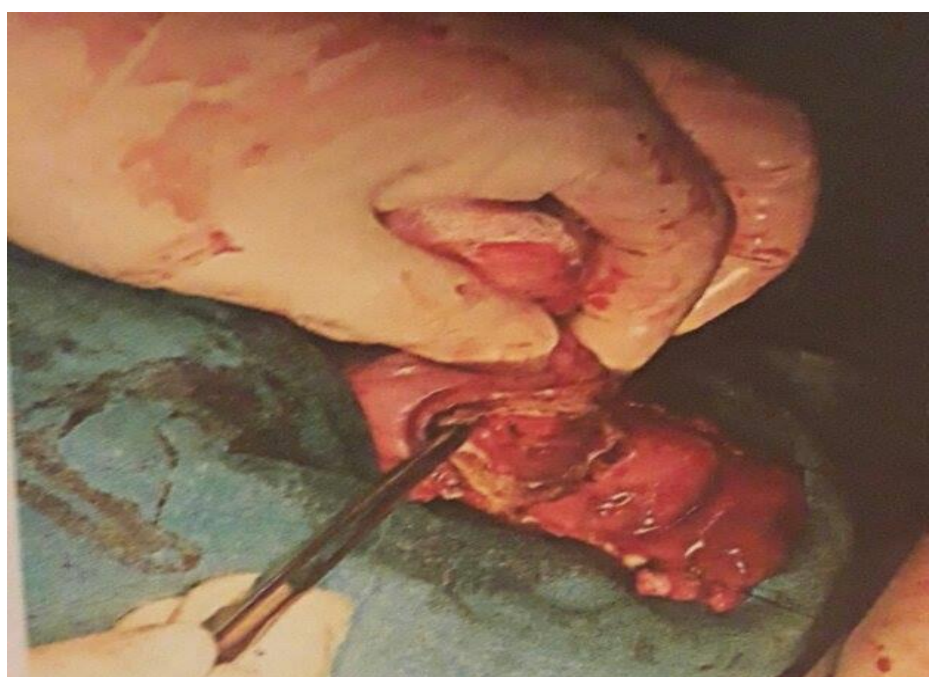

Fig-4: Exploring laparotomy confiremed the diagnosos an excision with mucoclasia was practiced

\section{DisCUSSION}

Gastrointestinal duplication is a relatively rare anomaly that may occur at any level from oral cavity to rectum with ileum being the most common site. Duplication cysts of the stomach are quite rare, and most of them have been reported in children $[1,5,6]$. Duplication cysts of ileum are usually located on mesenteric border [7], whereas the usual location for gastric duplication cysts is along the greater curvature theory of errors of recanalization and fusion of longitudinal folds. He suggested that duplication cysts originated from the fusion of longitudinal folds allowing the passage of a bridge of submucosa and muscle at the second and third month of intrauterine life [5]. Mc Letchie suggested that adhesion of notochord and embryonic endoderm might not elongate as quickly as its surrounding structures, causing traction diverticulum leading to duplication cyst formation [5]. Other theories of enteric duplication include abortive twinning, persistent embryological diverticula, and hypoxic or traumatic events [5]. There is no single theory that is satisfactory for all types of duplications [5]. Greater than $80 \%$ of gastric duplications are cystic and do not communicate with lumen of the stomach. There mainders are tubular with some communication [5]. The structure is defined as tubular when the lumen is contiguous and cystic when the lumen is not contiguous with stomach lumen [6]. The mucosal lining of duplication may be histologically similar to the segment of gut to which it is topographically related.

However, some duplications may include lining from other segment of alimentary or respiratory tract. The presence of respiratory epithelium in the cysts of thorax, tongue, liver, and stomach suggests that the undifferentiated epithelium of foregut might undergo transition to differentiated specialized epithelium during embryonic period [5]. Gastric duplications typically become symptomatic during childhood.67\% are diagnosed within the first year of life, and less than $25 \%$ are discovered after age 12 [4]. The duplication cysts of the stomach are usually diagnosed intraoperatively in adults [10].

The clinical presentation of gastric duplication cysts can be highly variable and nonspecific ranging from vague abdominal pain to nausea, vomiting, epigastric fullness, weight loss, anemia, dysphagia, dyspepsia with abdominal tenderness and epigastric mass on physical examination [4, 10]. Because most cases occur along the greater curvature of the stomach, the cysts can potentially compress the adjacent organs such as pancreas, kidney, spleen, and adrenal gland. Accordingly, the differential diagnosis would include lesions arising from these organs [2]. The cysts may also be manifested by complications such as infection, gastrointestinal bleeding, perforation, ulceration, fistula formation, obstruction, compression, or carcinoma arising in the cysts [7, 8]. Up to $10 \%$ of gastric duplications may contain ectopic pancreatic tissue which may lead to pancreatitis and mimic a pancreatic pseudocyst [3, 8]. Although it is difficult to diagnose GDC preoperatively, recent imaging modalities have provided some informative findings. CT scan and endoscopic ultrasound (EUS) are the best ways to identify GDC [8]. Classically, radiographic studies show an intramural filling defect indenting the gastric contour [8]. Contrast-enhanced CT scan typically demonstrates GDC as a thick-walled cystic lesion with enhancement of the inner lining [2].

Complete removal is the treatment choice to avoid the risk of possible complications such as obstruction, torsion, perforation, hemorrhage, and malignancy $[9,10]$. A Non communicating GDC is classically treated by complete excision of the cyst and resection of the shared wall between stomach and the duplication cyst [8]. Drainage and marsupialization of the cyst have been suggested. However, marsupialization into the stomach exposes the unprotected mucosa of the cyst to gastric contents with the risk of ulceration [4]. Drainage procedures such as cystojejunostomymay be complicated by stenosis of the 
anastomosis or blind loop syndrome and therefore discouraged [4]. Furthermore, leaving the cyst in place is illadvised given the potential for malignant transformation [4].

\section{CONCLUSION}

Gastric duplications are a rare condition in children. Diagnosis relies on histology, and treatment can only be by means of surgery. The outcome after surgery is generally favourable. Diagnosis and precocious surgeryof gastric duplciation can warm serious complications.

\section{REFERENCE}

1. Wieczorek RL, Seidman I, Ranson JH, Ruoff M. Congenital duplication of the stomach: case report and review of the English literature. Am J Gastroenterol. 1984;79:597-602.

2. Perek A, Perek S, Kapan M, Goksoy E. Gastric duplication cyst. Dig Surg. 2000;17:634-6.

3. Kim SM, Ha MH, Seo JE, Kim JE, Min BH, Choi MG, et al. Gastric duplication cysts in adults: a report of three cases. J Gastric Cancer. 2015;15:58-63.

4. Lee TC, Kim ES, Ferrell LB, Brandt ML, Minifee PK, Midgen C, Domingo RP, Kearney DL. Gastric duplication cysts of the pancreas: clinical presentationnand surgical management. Euro J Ped Surg. 2011;21:402-4.

5. Fox RT, Fowler JT Jr. Duplication of the alimentary tract. J Ped. 1952;41:194-7.

6. Kuraoka K, Nakayama H, Kagawa T, Ichikawa T, Yasui W. Adenocarcinoma arising from a gastric duplication cyst with invasion to the stomach: a case report with literature review. J Clin Pathol. 2004;57:428-31.

7. Johnston J, Wheatley GH 3rd, El Sayed HF, Marsh WB, Ellison EC, Bloomston M. Gastric duplication cysts expressing carcinoembryonic antigen mimicking cystic pancreatic neoplasms in two adults. Am Surg. 2008;74:91-4.

8. Horne G, Ming-Lum C, Kirkpatrick AW, Parker RL. High-grade neuroendocrine carcinoma arising in a gastric duplication cyst: a case report with literature review. Int J Surg Pathol. 2007;15:18791.

9. Tanaka M, Akahoshi K, Chijiiwa Y, Sasaki I, Nawata H. Diagnostic value of endoscopic ultrasonography in an unusual case of gastric cyst. Am J Gastroenterol. 1995;90:662-3.

10. Takahara $\mathrm{T}$, Torigoe $\mathrm{T}$, Haga $\mathrm{H}$, Yoshida $\mathrm{H}$, Takeshima S, Sano S, Ishii Y, Furuya T, Nakamura E, Ishikawa M. Gastric duplication cyst: evaluation byendoscopic ultrasonography and magnetic resonance imaging. J Gastroenterol. 1996;31:420-4. 